Acta vet. scand. $1988,29,135-137$.

Brief Communication

\title{
Technical Evaluation of a Naso-Ruminal Instrument for Collection of Ruminal Samples in Non-Fistulated Cows
}

The sampling method used is of great importance for the estimation of the microbial activity and biochemical status in ruminal fluid (Stöber \& Tiefenbach 1958, Keindorf 1974, Behravesh 1984). Several methods have been used for sampling of ruminal fluid in non-fistulated animals (Sørensen \& Schambye 1955, Perk 1958, Schultz \& Hiepe 1958, Keindorf \& Link 1971). However, the conventional methods of collecting ruminal fluid either by stomach tube (Thygesen probe with a filter ad modum Sørensen \& Schambye (1955)), or through a puncture low in the left flank, do not produce representative samples comparable in quality or quantity to samples collected directly through a rumen fistula. The puncture methods usually produce a very small volume of material, and they often leave the cow with an inflammatory reaction in the flank. Many research workers have demonstrated contamination with saliva in samples drawn through a peroral stomach tube, resulting inter alia in a higher $\mathrm{pH}$ value than in samples collected through fistula (Dirksen 1970, Behravesh 1984). Since changes in the fermentative reactions of high-yielding cows are receiving much research emphasis today, it has been our aim to construct an instrument suitable for collecting single or continuous samples for diagnostic as well as research purposes, which are comparable in quality and quantity to samples obtained through a rumen fistula. The idea of making the naso-ruminal sampler was inspired by the construction of the COMET Naso-Reticular Instrument (Hekmati et al. 1985).
The naso-ruminal sampler* consists of the following components:

a. Drinkwater's mouth gag.

b. A simple introductory plastic tube ( $\varnothing 5$ $\mathrm{mm}$, length $1.40 \mathrm{~m}$ ), which is passed through the naso-pharyngeal region (Fig. 1A) and connected to the main suction unit.

c. A retractor for the introductory tube, consisting of a ring on a $50 \mathrm{~cm}$ long handle (Fig. 1 A-B).

d. The main suction unit consisting of a suction head (Fig. 1 C) with many outside perforations ( $\varnothing 4 \mathrm{~mm}$ ) and a tube (outside $ø 8 \mathrm{~mm}$, inside $ø 6 \mathrm{~mm}$, length $2.20 \mathrm{~m}$ ) connected to it. The tube is made of relatively stiff, but flexible, material. The suction unit is introduced through the mouth, oesophagus and into the centre of the rumen by means of

e. A $1.85 \mathrm{~m}$ long cannula made of hard, plastic material. The cannula is pushed over the tube to fit into a lock on the suction head (Fig. IC). The cannula is bent in such a way that it will direct the suction unit through the ruminal contents into the ventral sac of the rumen (Fig. $1 \mathrm{E}$ ).

f. A hook-like instrument (Fig. 1 F) to catch the tube in the pharynx (mind the soft palate) and retrieve the suction unit (Fig. 1 G).

The Drinkwater mouth gag is placed between the cheek teeths, and the retractor is

*COMET Naso-Ruminal Sampler, O \& P Veterinary Equipment, Industrileddet 19, Svogerslev, DK-4000 Roskilde, Denmark. 
A
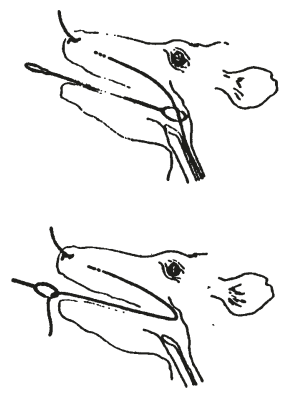

B

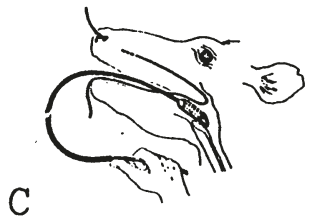

C

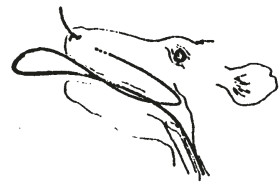

D

$\mathrm{F}$
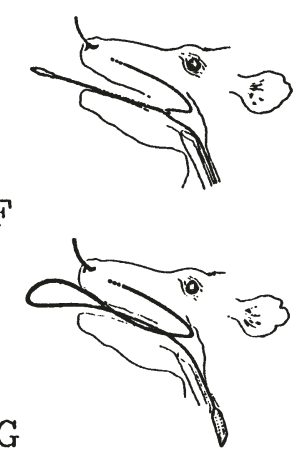

Figs. 1A-G illustrate the introduction (Figs. 1A-E) and the retraction (Figs. 1F-G) of the Comet NasoRuminal Sampler. (Drawings by Ivan Jönsson and Mette Mortensen).

placed in the pharynx. The introductory tube is passed through the nostril and into the oesophagus (Fig. 1A). The retractor containing the tube is withdrawn through the mouth (Fig. 1B). In some cases it may be necessary to help with the fingers.

The cannula is passed over the suction tube, locked into the suction head and kept in place by pressing the thumb against the cannula (Fig. 1C). The cannula and suction unit are passed through the mouth and oesophagus to the ventral sac of the rumen. Then the cannula is released and withdrawn, and the end of the suction tube is connected to the introductory tube, which is drawn out through the nose and secured to the halter (Fig. 1D) whereafter the mouthgag is retracted.

The animal is able to eat, eructate, and ruminate with the instrument in position, even for long periods (days, weeks).

For retraction of the suction unit, the drinkwater mouth gag is again applied, and the sampling tube is retrieved from the pharyngeal cavity with the hooked instrument (Fig. 1F). If it is impossible to catch the tube with the hook, then the hand may be used. The introductory tube is untied from the halter, and the suction unit can be withdrawn.

On testing the present instrument it was found that when the head of the animal was well fastened, insertion of the instrument took only 2-3 min. At the beginning of our experiments, a suction head ad modum Sørensen \& Schambye was used with poor results. It was, therefore, also necessary to design a new suction head. The Sørensen \& Schambye suction unit was designed for transfusion of ruminal contents and not for collecting samples of ruminal fluid for biochemical analysis.

The present suction head tapers off at the end. It is perforated to keep out the coarse particles and at the same time allowing as mush space for suction as possible. The suction head has no internal filter and can easily be cleaned with a compressed-air stream. By means of a slight vacuum it is possible to obtain a steady flow of ruminal fluid without bubbles in a short time. Often, it is also possible to obtain ruminal fluid without suction because the pressure in the rumen will force the fluid out and continue to do so according to the principle that water seeks its own level. With the new suction unit it took $20 \mathrm{~s}$ to collect $400 \mathrm{ml}$ fluid into a thermojar, whereas it took more than $40 \mathrm{~s}$, sometimes even several minutes, with the Sørensen \& Schambye suction head.

Two animals were provided with rumen fistulas for comparative sampling and control of the position of the suction head. It was 
found that the suction unit mounted with the cannula easily penetrated feedstuff and the suction unit remained in the ventral ruminal sac until it was removed. Even in cases of relatively dry rumen material, ruminal fluid could be obtained by suction.

In a number of test animals the suction unit was left in the rumen for 2-3 weeks without any observable untoward results. Care should be taken to ensure that the tube passing through the nostril is tied in such a way that it cannot get caught on anything in the cow house, so that the cow could get hold of the tube and damage it; than the suction unit would probably be lost unless the tube is reenforced by wire in its wall.

Continuous sampling from the abomasum has hitherto been difficult. However, it should be possible to place the present instrument, possibly with a smaller suction head, in the abomasum via the omaso-abomasal tract and by manipulation via a rumenotomy opening.

A report on the clinical-chemical examination results relating to the naso-ruminal sampler is being published by Poulsen et al. (1988).

\section{Acknowledgement}

The authors wish to thank Miss. A. Jensen, Development Cooperation Bureau, Royal Veterinary and Agricultural University, Copenhagen for correction of the English language.

\section{J. S. Dirch Poulsen,}

Royal Veterinary and Agricultural University, Dept. of Surgery.

Fl. Olesen,

$\mathrm{O}$ and $\mathrm{P}$ Veterinary equipment ApS.

P. Hekmati and G. A. Bakshodeh,

University of Tehran, Tehran, Iran.

\section{References}

Behravesh S: Examination of the Ruminal Fluid and Blood of Bovines fed different Diets. A Bioche- mical, Clinical Chemical, Microbiological and Physical Study. Ph. D. thesis, Department of Surgery, The Royal Veterinary and Agricultural University, Copenhagen, Denmark 1984.

Dirksen G: Acidosis. In Physiology of Digestion and Metabolism in the Ruminant. Edited by A. T. Philipson, Great Britain, Oriel Press, Newcastle upon Tyne, 1970, p. 350-361.

Hekmati P, Bakshodeh G A, Poulsen J S D: Traumatic Reticulitis. The COMET Naso-Reticular Instrument for Withdrawal of Foreign Bodies from the Reticulum of Cattle. Nord. Vet. Med. 1985, 37, 338-348.

Keindorf H-J: Weitere Anwendungsmöglichkeiten eines modifizierten Pansensaftentnahmegerätes in der Buiatrik. (Further possibilities for use of a modified instrument for collection of ruminal fluid in the cattle clinic) Mh. Vet. Med. 1974, 29, 688-691.

Keindorf H-J, Link R: Zur Praxis der Pansensaftentnahme beim Rind. (Practice of collection of ruminal juice in cattle). Mh. Vet.-Med. 1971, 26, 137-139.

Perk K: Eine praktische Methode für die Pansensaftentnahme bei Schaf und Rind. (A practical method of collection of ruminal juice in sheep and cattle). Schweiz. Arch. Tierhk., 1958, 100, 167-170.

Poulsen J S D, Özkan K, Andersen J O: A Clinical Chemical Comparative Examination of Ruminal Samples collected by means of a Naso-Ruminal Sampler. Acta vet. scand. 1988, 29, 129-133.

Schultz J A, Hiepe Th: Beitrag zur Technik der Pansensaftentnahme. (Collection of ruminal juice). Berl. u. Münch. tierärztl. Wschr. 1985, 71, 330331.

Stöber M, Tiefenbach B: Pansensaftgewinnung und Vormagenentleerung zu therapeutischen Zwecken - Prüfung der Brauchbarkeit von drei Instrumenten. (Collection of ruminal juice and emptying of rumen for therapeutical purpose Examination of the use of 3 instruments). Dt. tierärztl., Wschr. 1958, 65, 11-16.

Sørensen V, Schambye P: Apparatur til udtagelse af vomindhold. (Instrument for collection of ruminal content) Medlemsbl. f. den danske Dyrlægeforen., 1955, 38, 60-63.

(Received July 3, 1987).

Reprints may be requested from: J. S. Dirch Poulsen, Clinical Central Laboratory, Department of Small Animal Diseases and Clinical Practice. Royal Veterinary and Agricultural University, Bülowsvej 13, DK-1870 Frederiksberg C, Denmark. 
